\title{
IMPLANTAÇÃO E DOCUMENTAÇÃO DO BANCO ATIVO DE GERMOPLASMA DE LIPPIA ORIGANOIDES H.B.K (VERBENACEAE) E EPLINGIELLA FRUTICOSA (SALZAM EX. BENTH) HARLEY E J.F.B PASTORE (LAMIACEAE)
}

\author{
Vanessa Chaves da Franca ${ }^{1}$; Lenaldo Muniz de Oliveira² ${ }^{2}$ Romeu da Silva Leite ${ }^{3}$; \\ Emily Verônica Rosa da Silva Feijóo \\ 1. Bolsista PIBIC/CNPq, Graduando em Agronomia, Universidade Estadual de Feira de Santana, e-mail: \\ vanessafranca2011@hotmail.com \\ 2. Orientador, Departamento de Ciências Biológicas, Universidade Estadual de Feira de Santana, e-mail: \\ lenaldo.uefs@gmail.com \\ 3. Participante do projeto, Graduando em Agronomia, Universidade Estadual de Feira de Santana, e-mail: \\ leiteromeu@hotmail.com \\ 4. Participante do projeto, Doutoranda em RGV, Universidade Estadual de Feira de Santana, e-mail: \\ emillyfeijo@hotmail.com
}

PALAVRAS-CHAVE: plantas medicinais; BAG; conservação de RGV.

\section{INTRODUÇÃO}

O semiárido brasileiro reserva grande riqueza e diversidade de espécies úteis a população local, sendo comum o uso de espécies vegetais para fins medicinais. Alguns grupos, como Lippia (Verbenaceae) e Hyptis (Lamiaceae) destacam-se por seu grau de endemismo e seu metabolismo, o que permite o uso diversificado, através de propriedades antimicrobiana, antifúngica e anti-inflamatória (Falcão \& Menezes, 2003). No entanto, os ambientes naturais vêm sofrendo grande degradação devido a ações antrópicas, fazendo com que ocorra a perda de espécies e genótipos. Por esse motivo, a implantação de Bancos Ativos de Germoplasma (BAG) é a principal estratégia para conservação ex situ, geralmente destinado a espécies para fins de pesquisa, melhoramento e uso desses recursos.

A espécie Lippia origanoides H.B.K (Verbenaceae) é um arbusto aromático, nativo da América Central e do norte da América do Sul. É utilizada na medicina tradicional para o tratamento de doenças gastrointestinais e respiratórias (Vicuña; Stashenko; Fuentes, 2010) e, segundo Oliveira et al. (2007), seu óleo essencial é rico em timol, carvacrol e $\gamma$ terpineno. Essa espécie cresce em habitats selvagens e até o momento não foi encontrado nenhum estudo mostrando o desenvolvimento de variedades cultivadas, representando um risco em um cenário de colheita predatória (Castilho et al., 2013).

Eplingiella fruticosa (Salzm. ex Benth.) Harley \& J.F.B.Pastore (Lamiaceae), conhecida popularmente como "alecrim-de-vaqueiro", é uma planta nativa do nordeste brasileiro, aromática e de grande potencial medicinal e terapêutico (SILVA, 2015). Contudo, não há registro de estudos sobre o cultivo dessa espécie, o que tem aumentado a pressão sobre as populações naturais, na medida em que seu uso atual encontra-se limitado ao extrativismo (SILVA, 2015).

Diante do exposto, o presente estudo objetivou a implantação e documentação do banco ativo de germoplasma das espécies Lippia origanoides H.B.K e Eplingiella fruticosa (Salzm ex Benth.) Harley \& J.F.B.Pastore na Unidade Experimental Horto Florestal (UNEHF) da Universidade Estadual de Feira de Santana (UEFS), a fim de promover a conservação da diversidade e ampliação do conhecimento sobre as espécies. 


\section{MATERIAL E MÉTODOS}

O BAG foi implantado no UNEHF/UEFS, Feira de Santana-BA, coordenadas $12^{\circ} 15^{\prime}$ $24^{\prime \prime} \mathrm{S}$ e $37^{\circ} 57^{\prime} 53^{\prime}$ W, com altitude média de $230 \mathrm{~m}$. O BAG de L. origanoides foi constituído por 13 acessos diferentes (Tabela 1), coletados em diferentes municípios da Bahia. Os acessos foram propagados através de estacas e permaneceram em casa de vegetação por aproximadamente 60 dias, sendo transferidas definitivamente para o canteiro definitivo, onde foram plantadas quatro plantas com espaçamento de $0,5 \mathrm{~m}$ entre plantas (Figura 1). O plantio foi realizado em covas com 30x30x30 cm, fertilizadas com esterco bovino na proporção de $1 / 2$ litro por cova. Após o plantio os canteiros foram cobertos com folhas secas (cobertura morta) para reduzir a evoparação da água e reduzir o crescimento de ervas daninhas. Para manutenção dos acessos foram realizadas irrigações manuais, a cada três dias e capinas e podas de limpeza a cada dois meses. Foram realizadas vistorias semanais para identificação de pragas e doenças e, quando necessário, foi realizado a aplicação de inseticida natural a base de fumo, citronela e sabão neutro. Após a implantação do BAG cada acesso foi identificado com placas de acrílico contendo o nome da espécie, a família botânica e o número do acesso. Foi criado um catálogo com informações ecogeográficas, morfo-agronômicas e fitoquímicas de cada acesso.

Os acessos de Eplingiella fruticosa não foram implantados no banco de germoplasma devido a dificuldades de propagação das mudas, no entanto, os acessos ainda estão sendo propagados.

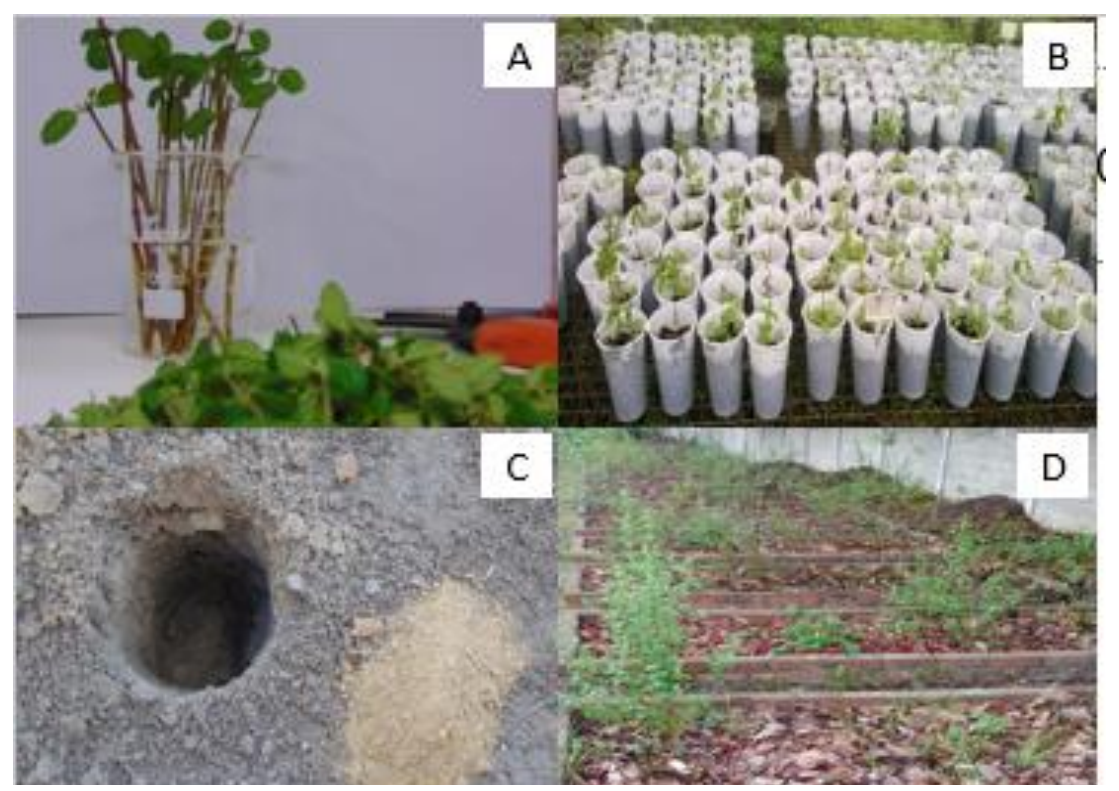

Figura 1. Propagação dos acessos Lippia origanoides H.B.K. por estacas (A), estacas plantadas em copos (B), cova com adubo orgânico (C), mudas transplantadas para o canteiro definitivo (D).

\section{RESULTADOS E DISCUSSÃO}

Os 13 acessos de L. origanoides implantados no BAG da UNEHF/UEFS, assim como os locais de coleta estão descritos na Tabela 1. 
Tabela 1. Acessos de Lippia origanoides H.B.K. que compõem o banco ativo de germoplasma da espécie na Unidade Experimental do Horto Florestal da Universidade Estadual de Feira de Santana (UNEHF/UEFS). Feira de Santana, 2017.

\begin{tabular}{|c|c|c|c|c|}
\hline GENÓTIPO & LOCAL COLETA & LONGITUDE (0) & LATITUDE (S) & ALTITUDE (M) \\
\hline L.0. 001 & Santa Barbara & $38^{\circ} 58^{\prime} 15,5^{\prime \prime}$ & $12^{\circ} 01^{\prime} 04,5^{\prime \prime}$ & 270 \\
\hline L.0. 002 & Jequié & $40^{\circ} 03^{\prime} 28,6^{\prime \prime}$ & $13^{\circ} 45^{\prime} 09,4^{\prime \prime}$ & 346 \\
\hline L.0. 003 & Nova Itarana & $39^{\circ} 56^{\prime} 05,6^{\prime \prime}$ & $12^{\circ} 58^{\prime} 22,0^{\prime \prime}$ & 526 \\
\hline L.0. 004 & Quixabeira & $40^{\circ} 07^{\prime} 39,1^{\prime \prime}$ & $11^{\circ} 20^{\prime} 03,9^{\prime \prime}$ & 396 \\
\hline L.0. 005 & Casa Nova & $40^{\circ} 58^{\prime} 15,0^{\prime \prime}$ & $09^{\circ} 09^{\prime} 43,0^{\prime \prime}$ & 417 \\
\hline L.0. 006 & Jaguarari & $40^{\circ} 13^{\prime} 58,0^{\prime \prime}$ & $10^{\circ} 05^{\prime} 20,4^{\prime}$ & 543 \\
\hline L.0. 007 & Riachão do Jacuípe & $39^{\circ} 26^{\prime} 12,6^{\prime \prime}$ & $11^{\circ} 46^{\prime} 54,6^{\prime \prime}$ & 193 \\
\hline L.0. 008 & Santa Teresinha & $39^{\circ} 32^{\prime} 14,8^{\prime \prime}$ & $12^{\circ} 35^{\prime} 46,8^{\prime \prime}$ & 140 \\
\hline L.0. 009 & Santaluz & $39^{\circ} 24^{\prime} 50,0^{\prime \prime}$ & $11^{\circ} 12^{\prime} 30,4^{\prime \prime}$ & 348 \\
\hline L.0. 010 & Santa Brígida & $38^{\circ} 15^{\prime} 43,9^{\prime \prime}$ & $09^{\circ} 50^{\prime} 16,4^{\prime \prime}$ & 397 \\
\hline L.O. 011 & Jeremoabo & $38^{\circ} 49^{\prime} 23,7^{\prime \prime}$ & $11^{\circ} 01^{\prime} 25,5^{\prime \prime}$ & 227 \\
\hline L.0. 012 & Tucano & $38^{\circ} 17^{\prime} 54,4^{\prime \prime}$ & $10^{\circ} 13^{\prime} 35,7^{\prime \prime}$ & 354 \\
\hline L.0. 013 & Sento Sé & $41^{\circ} 53^{\prime} 06,0^{\prime \prime}$ & $09^{\circ} 44^{\prime} 45,0^{\prime \prime}$ & 400 \\
\hline
\end{tabular}

Os acesso apresentaram crescimento e desenvolvimento adequado, o que permitiu a manutenção dos mesmos na coleção (Figura 02).

Figura 2. Banco Ativo de Germoplasma da espécie Lippia origanoides H.B.K. implantado na Unidade Experimental do Horto Florestal da Universidade Estadual de Feira de Santana (UNEHF/UEFS). Mudas com dois meses no momento do transplante (A) e plantas com dez meses no BAG (B). Feira de Santana, 2017.

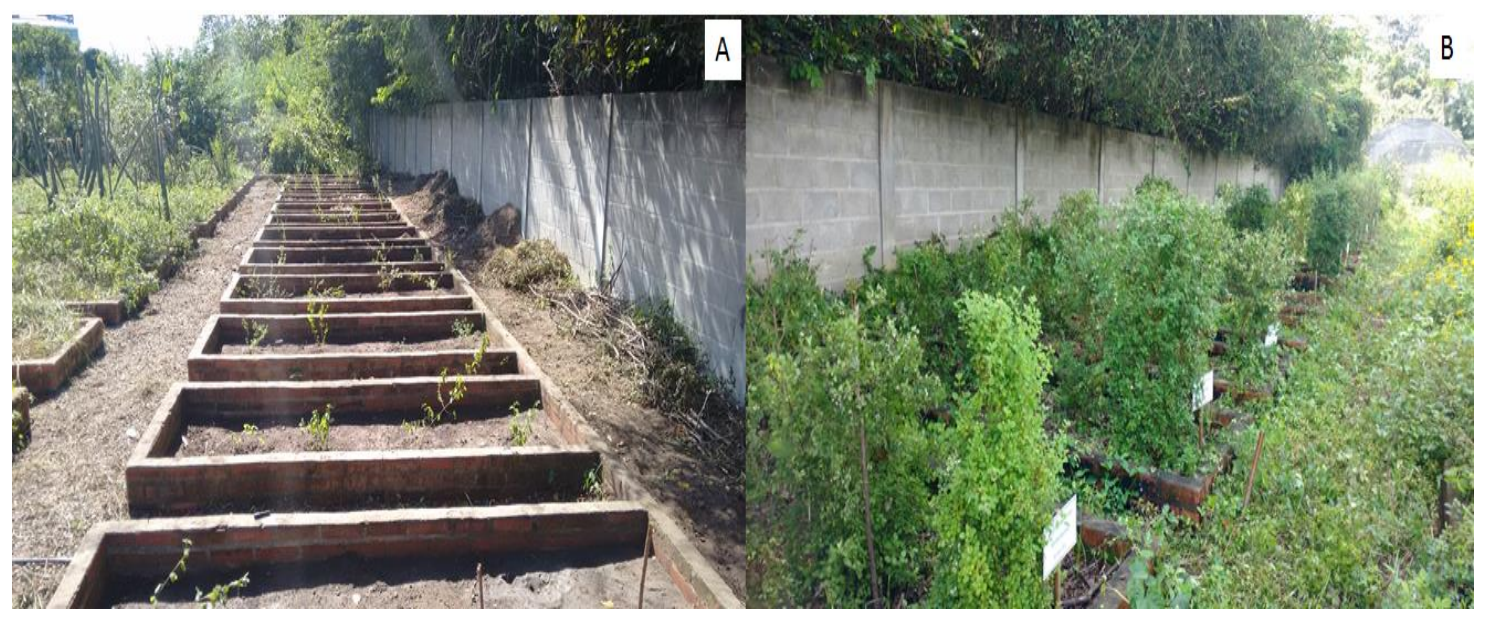

A caraterização morfológica dos acessos demonstrou grande variação na altura das plantas, comprimento foliar, largura foliar, relação comprimento/largura de folha e coloração dos caules (dados apresentados no relatório de I.C. 2016). Da mesma forma, a caracterização fitoquímica demonstrou grande variação no teor e composição dos óleos essenciais. O teor de óleo variou de $1,04 \%$ no acesso coletado em Jeremoabo a 8,09\% no acesso coletado no município de Sento Sé (Tabela 02). As análises demonstraram a ocorrência dos quimiotipos "timol" e "carvacrol" e alguns acessos com compostos majoritários não comum aos quimiotipos já conhecidos, o que sugere se tratar de quimiotipos novos (Tabela 02). 
Tabela 2. Teor de óleo essencial e constituintes majoritários dos acessos da espécie Lippia origanoides H.B.K. mantidos no banco ativo de germoplasma da Unidade Experimental do Horto Florestal da Universidade Estadual de Feira de Santana (UNEHF/UEFS). Feira de Santana, 2017.

\begin{tabular}{|c|c|c|c|}
\hline GENÓTIPO & LOCAL COLETA & QUIMIOTIPO & $\begin{array}{l}\text { TEOR DE ÓLEO g / } \\
100 \mathrm{~g} \text { FOLHA }\end{array}$ \\
\hline L.0. 001 & Santa Barbara & Carvacrol & 2,95 \\
\hline L.0. 002 & Jequié & Timol & 2,44 \\
\hline L.0. 003 & Nova Itarana & Timol & 3,16 \\
\hline L.0. 004 & Quixabeira & Carvacrol/Cânfora & 3,29 \\
\hline L.0. 005 & Casa Nova & Carvacrol & 3,82 \\
\hline L.0. 006 & Jaguarari & Carvacrol & 5,61 \\
\hline L.O. 007 & Riachão do Jacuípe & Carvacrol & 3,23 \\
\hline L.0. 008 & Santa Teresinha & Carvacrol & 3,20 \\
\hline L.0. 009 & Santaluz & Carvacrol & 2,79 \\
\hline L.0. 010 & Santa Brígida & Acetato de linalol & 3,08 \\
\hline L.O. 011 & Jeremoabo & E-cariofileno & 1,04 \\
\hline L.0. 012 & Tucanos & Carvacrol & 3,52 \\
\hline L.0. 013 & Sento Sé & Timol & 8,09 \\
\hline
\end{tabular}

Com base nos dados morfológicos e fitoquímicos coletados verifica-se que cada acesso apresentou características distintas, o que demonstra ser uma fonte de variabilidade genética da espécie. A partir dos resultados obtidos e manutenção dos acessos, trabalhos de melhoramento genético via seleção e hibridização poderão ser desenvolvidos, buscando-se a obtenção de cultivares mais produtivos.

\section{CONSIDERAÇÕES FINAIS}

Os acessos da espécie Lippia origanoides foram propagados e implantados com sucesso no local definitivo, apresentando bom crescimento e desenvolvimento, o que possibilitou a implantação do banco ativo de germoplasma da espécie.

\section{REFERENCIAS}

CASTILHO, C. V. V. et al. 2013. Composição química do óleo essencial de Lippia origanoides sob diferentes condições de cultivo in vitro. In: Simpósio Brasileiro de Óleos Essenciais (SBOE). Santarém. Anais... Santarém: Universidade Federal do Oeste do Pará.

FALCÃO, D. Q; MENEZES, F. S. 2003. Revisão etnofarmacológica, farmacológica e química do gênero Hyptis. Revista Brasileira de Farmácia. v. 84, n. 3, p. 69-74.

OLIVEIRA, D.R.; LEITÃO, G. G.; BIZZO, H. R.; LOPES, D.; ALVIANO, D. S.; ALVIANO, C. S.; LEITÃO, S. G. 2007. Food Chemistry, 101, 236-240p.

VICUÑA, G. C; STASHENKO, E. E.; UENTESF, J. L. 2010. Chemical composition of the Lippia origanoides essencial oils and their antigenotoxicity against bleomycininduced DNA damage. Fitoterapia, v. 81, p. 343-349.

SILVA, A. C. 2015. Caracterização agronômica, molecular e fitoquímica de Eplingiella Harley \& J.F.B PASTORE. Tese (Doutorado) - Universidade Estadual de Feira de Santana, Feira de Santana, 125 p. 